\title{
Review of Recent Developments on Using an Off-Lattice Monte Carlo Approach to Predict the Effective Thermal Conductivity of Composite Systems with Complex Structures
}

\author{
Feng Gong ${ }^{1,2}$, Hai M. Duong ${ }^{3}$ and Dimitrios V. Papavassiliou ${ }^{2, *}$ \\ 1 School of Energy Science and Engineering, University of Electronic Science and Technology of China, \\ Chengdu 610000, China; gongfeng@u.nus.edu \\ 2 School of Chemical, Biological, and Materials Engineering, University of Oklahoma, Norman, \\ OK 73019, USA \\ 3 Department of Mechanical Engineering, National University of Singapore, Singapore 117576, Singapore; \\ mpedhm@nus.edu.sg \\ * Correspondence: dvpapava@ou.edu; Tel.: +1-405-325-0574
}

Academic Editors: Xianqiao Wang and Tienchong Chang

Received: 17 June 2016; Accepted: 27 July 2016; Published: 30 July 2016

\begin{abstract}
Here, we present a review of recent developments for an off-lattice Monte Carlo approach used to investigate the thermal transport properties of multiphase composites with complex structure. The thermal energy was quantified by a large number of randomly moving thermal walkers. Different modes of heat conduction were modeled in appropriate ways. The diffusive heat conduction in the polymer matrix was modeled with random Brownian motion of thermal walkers within the polymer, and the ballistic heat transfer within the carbon nanotubes (CNTs) was modeled by assigning infinite speed of thermal walkers in the CNTs. Three case studies were conducted to validate the developed approach, including three-phase single-walled CNTs/tungsten disulfide $\left(\mathrm{WS}_{2}\right) /($ poly $($ ether ether ketone) (PEEK) composites, single-walled CNT/ $\mathrm{WS}_{2} / \mathrm{PEEK}$ composites with the CNTs clustered in bundles, and complex graphene/poly(methyl methacrylate) (PMMA) composites. In all cases, resistance to heat transfer due to nanoscale phenomena was also modeled. By quantitatively studying the influencing factors on the thermal transport properties of the multiphase composites, it was found that the orientation, aggregation and morphology of fillers, as well as the interfacial thermal resistance at filler-matrix interfaces would limit the transfer of heat in the composites. These quantitative findings may be applied in the design and synthesis of multiphase composites with specific thermal transport properties.
\end{abstract}

Keywords: off-lattice Monte Carlo simulation; multiphase polymer composites; carbon nanotube; graphene; thermal conductivity

\section{Introduction}

Polymer composites can combine the merits of fillers and polymer matrix in a hybrid system. They can even replace the traditional materials (e.g., glass-based materials, metals and alloys) in a number of applications, due to their unique optical, mechanical, thermal and electrical properties [1]. During recent years, carbon-based two-phase polymer composites, such as carbon nanotube (CNT)-polymer composites and graphene-polymer composites, have attracted much attention from both academy and industry, owing to their superior strength, high thermal conductivity and good electrical conductivity [2-4]. In general, the thermal conductivity and electrical conductivity of carbon 
additives (e.g., CNTs, graphene, carbon black, carbon fiber) are both much higher than those of polymer matrices.

With the additions of carbon fillers into polymers, both the thermal and electrical conductivity of composites can be significantly enhanced, which may limit the applications of composites in some specific fields. For instance, in electronic packaging, the packaging materials require high thermal conductivity but low electrical conductivity. Two-phase composites with only one type of carbon filler are difficult to achieve this requirement. Multi-types of fillers are required to enhance thermal conductivity but retain electrical insulation for composites. For example, Dai et al. developed polyimide (PI) composites containing one-dimensional (1D) SiC nanowires and two-dimensional (2D) graphene nanosheets as hybrid fillers [5]. As the 1D SiC nanowires prevent the graphene nanosheets forming networks, the three-phase composite achieves a low electrical conductivity $\left(\sim 1.32 \times 10^{-10} \mathrm{~S} / \mathrm{cm}\right)$ but a high thermal conductivity $(\sim 0.577 \mathrm{~W} / \mathrm{m} \cdot \mathrm{K})[5]$.

On the other hand, as electronic devices are developing to the integrated and micro-scale level, thermal interface materials (TIMs) with high thermal conductivity are necessary to effectively dissipate the heat and then to protect electronic devices [6,7]. Traditional TIMs with one type of filler require high loading of fillers to achieve the expected thermal conductivity of $0.5-5 \mathrm{~W} / \mathrm{m} \cdot \mathrm{K}$, which dramatically increases the cost and the viscosity of the composite. Recently, it has been found that combining multiple fillers in polymer may significantly enhance the thermal conductivity of the composites owing to the synergistic effect of fillers. Zhao et al. obtained a three-phase composite by adding $0.2 \mathrm{vol} \%$ graphene foam (GF) and $2.7 \mathrm{vol} \%$ multilayer graphene flakes (MGFs) into polydimethylsiloxane (PDMS). Due to the synergistic effect of GF and MGFs, the MGF/GF/PDMS composites achieved a thermal conductivity of up to $1.08 \mathrm{~W} / \mathrm{m} \cdot \mathrm{K}$, which is $440 \%, 184 \%$ and $80 \%$ higher than those of pure PDMS, 0.2 vol \% GF/PDMS and $2.7 \mathrm{vol} \%$ MGF/PDMS composites, respectively [8].

In addition to the above multiphase composites, other diverse types of multiphase composites have been developed for their specific applications, such as CNT/inorganic nanoparticle/polymer [9,10], CNT/graphene/polymer [11-13], graphene/inorganic nanoparticle/polymer [14,15], and polymer blends $[16,17]$. Such multiphase composites can combine the merits of fillers and matrix to achieve advanced properties for diverse applications. Experimental measurements have shown that the effective thermal conduction properties of multiphase composites can be significantly enhanced due to the synergistic effects of fillers. However, computational studies in this field are still limited due to the complex structure and composition of multiphase composites. The effective medium theory has been used to estimate the effective thermal conductivity $\left(K_{\text {eff }}\right)$ of multiphase composites [18]. The $K_{\text {eff }}$ is calculated in separated steps, which neglects the synergistic effect of fillers. An effective modeling of heat transfer in multiphase composites can reveal the thermal transport phenomena and limitations in them, which may help to design multiphase composites with specific thermal properties.

In this article, we review an effective approach to model the heat transfer in multiphase composites with complex structures based on our work about the computational studies on the effective thermal properties of multiphase composites. The paper is organized as following: In Simulation Methods, an off-lattice Monte Carlo approach for modeling heat transfer in a three-phase composite is presented in detail. Three case studies are discussed in Results and Discussion to demonstrate the novelty, accuracy and superiority of the developed approach. The case-study systems include three-phase single-walled CNT (SWNT)/tungsten disulfide $\left(\mathrm{WS}_{2}\right) /$ poly(ether ether ketone) (PEEK) composite, four-phase SWNT/SWNT bundle/WS 2 /PEEK composite, and complex graphene/poly(methyl methacrylate) (PMMA) composite. We quantitatively studied the factors influencing the thermal transport in multiphase composites, such as the morphology, dispersion, alignment and concentration of fillers, as well as the effects of the interfacial thermal resistance between any pair of components. Such quantitative findings may guide researchers to design and synthesize multiphase composites with specific thermal transport properties. 


\section{Simulation Methods}

In this section, we chose a three-phase SWNT/ $\mathrm{WS}_{2} / \mathrm{PEEK}$ composite to illustrate the off-lattice Monte Carlo approach. The off-lattice Monte Carlo approach regards the heat flow as the result of the movement of discrete thermal walkers with random motion [19]. The Monte Carlo approach has been successfully applied to model heat or mass transport in flow through porous materials $[20,21]$ and in convective flows [22,23]. A three-dimensional (3D) model was built based on the SWNT/WS $/$ PEEK composite fabricated by Naffakh et al. [9]. As shown in Figure 1a, SWNTs (500 nm length and $2 \mathrm{~nm}$ diameter) and $\mathrm{WS}_{2}$ spherical nanoparticles (110 $\mathrm{nm}$ diameter) were randomly and uniformly dispersed in PEEK matrix (925 nm side length). The mass fractions of SWNTs, $\mathrm{WS}_{2}$ nanoparticles and PEEK were $0.5 \mathrm{wt} . \%, 0.5 \mathrm{wt}$. \% and $99.0 \mathrm{wt}$. \%, respectively. The 3D model is a representative volume element (RVE) of the three-phase composite, which can be repeated to accurately replicate the realistic composite samples.

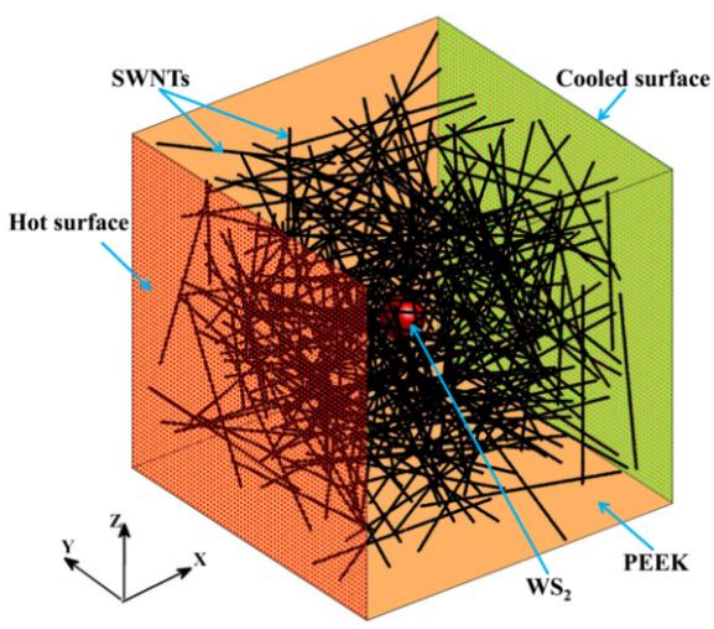

(a)

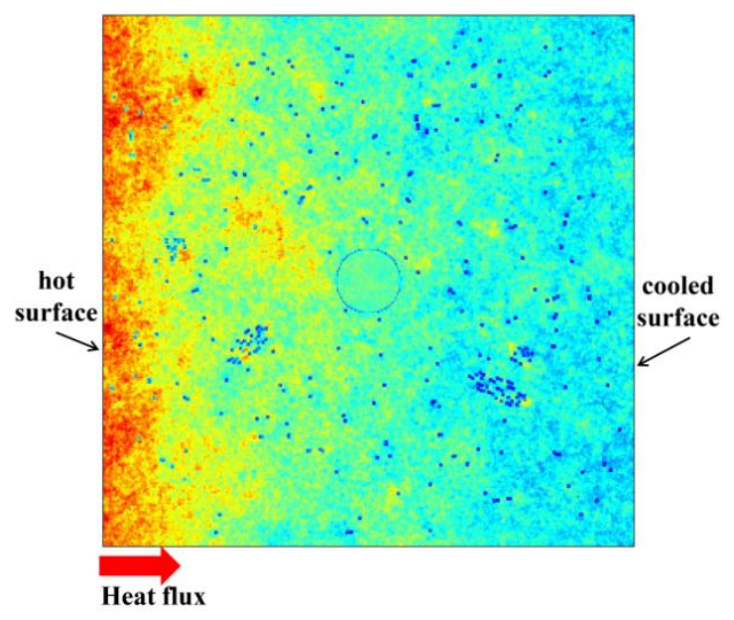

(b)

Figure 1. A schematic plot of the SWNT/WS $/$ PEEK model: (a) a $\mathrm{WS}_{2}$ nanoparticle (110 nm diameter) is placed in the center of a PEEK cube with a side length of $925 \mathrm{~nm}$, while 317 SWNTs ( 2 nm diameter and $500 \mathrm{~nm}$ length) are randomly distributed in the PEEK cube. The $\mathrm{WS}_{2}$ particle is painted red and the nanotubes are black in the figure. Constant heat flux is applied along the $x$ direction by creating a hot surface and a cooled surface (Reproduced with permission from [18]. Copyright Elsevier, 2015); (b) a contour plot of thermal walker distribution in the center $x y$ plane of the SWNT/WS $2 / \mathrm{PEEK}$ model at the thermal steady state (Reproduced with permission from [24]. Copyright American Chemical Society, 2015).

To model the heat transfer in the composite, a constant heat flux was applied along $\mathrm{x}$-direction by continuously releasing a large quantity (e.g., 40,000) of thermal walkers from both sides in each time step (i.e., hot walkers from $x=0$, and cold walkers from the other side). The two sides can be treated as a hot and a cold surface, as presented in Figure 1a. The hot walkers and cold walkers (with negative energy) have same absolute value of energy, so the energy of the whole system is conserved. A thermal walker jumps randomly following a Brownian motion after released from the surfaces. The Brownian motion is described by position changes of thermal walkers in each direction. The position changes take values from a normal distribution with a zero mean and a standard deviation, $\sigma$, expressed as [25]: 


$$
\sigma=\sqrt{D_{m} \Delta t}
$$

where $D_{m}$ is the thermal diffusivity of the matrix and $\Delta t$ is the time step duration of the simulation. Thermal walkers travel randomly from the initial release surface. Once a thermal walker jumps to the interface between PEEK and a SWNT, it is allowed to either jump into the SWNT with a probability of $f_{\mathrm{m}-\mathrm{SWNT}}$, or still remains in the PEEK matrix with a probability of $\left(1-f_{\mathrm{m}-\mathrm{SWNT}}\right)$. The $f_{\mathrm{m}-\mathrm{SWNT}}$ is related to the interfacial thermal resistance (known as Kapitza resistance) between the PEEK matrix and SWNTs, which can be estimated from the acoustic mismatch theory, as follows [26]:

$$
f_{\mathrm{m}-\mathrm{SWNT}}=\frac{4}{\rho_{\mathrm{m}} C_{\mathrm{P}_{\mathrm{m}}} \nu_{\mathrm{m}} R_{\mathrm{bd}}}
$$

where $\rho_{\mathrm{m}}, C_{\mathrm{P}_{\mathrm{m}}}, v_{\mathrm{m}}$ and $R_{\mathrm{bd}}$ are the density of the PEEK matrix, the specific heat capacity of PEEK, the speed of sound in PEEK, and the interfacial thermal resistance between PEEK and SWNT, respectively. When a thermal walker jumps into a SWNT, it is assumed to travel with an infinite speed, due to the ballistic phonon transport and ultrahigh thermal conductivity of SWNTs [27]. The implementation of this assumption occurs by randomly placing the walker anywhere within the SWNT. The random placement is based on a uniform distribution function and it occurs in a single time step. The diffusivity inside the CNTs would need to be considered explicitly (using a second Gaussian random motion) if the CNTs were on the same order of magnitude or longer than the wavelength of a phonon. However, this case would present itself for much longer CNTs than the ones consider presently. When inside a SWNT, thermal walkers may exit the SWNT based on another probability, designated as $f_{\text {SWNT-m }}$. This probability is determined from $f_{\mathrm{m}-\mathrm{SWNT}}$, as [19]:

$$
V_{\text {SWNT }} f_{\text {SWNT-m }}=C_{f-\text { SWNT }} \sigma A_{\text {SWNT }} f_{\text {m-SWNT }}
$$

where $V_{\mathrm{SWNT}}$ and $A_{\mathrm{SWNT}}$ are the volume and surface area of SWNTs, and $C_{f-\mathrm{SWNT}}$ is a thermal equilibrium factor at the PEEK-SWNT interface which depends on the geometry of SWNTs and the interfacial area between PEEK and a SWNT. The thermal equilibrium factor is introduced in order to preserve the second law of thermodynamics at thermal equilibrium. The above relation between $f_{\text {SWNT-m }}$ and $f_{\mathrm{m} \text {-SWNT }}$ can be explained as follow: When reaching the thermal steady state, the heat flux exiting a SWNT should be equal to that entering the SWNT. In a time step, all thermal walkers inside a SWNT may travel to the PEEK matrix owing to their infinite speed. However, among the thermal walkers in PEEK, only those around the SWNT surface may jump into the SWNT due to the Brownian motion. In order to maintain a balanced heat flux exiting and entering a SWNT, the relation as described in Equation (3) should be satisfied.

When inside a $\mathrm{WS}_{2}$ nanoparticle, a thermal walker jumps randomly, similar to the way it travels in the PEEK matrix, but with a different thermal diffusivity (that of $W_{2}$ ) used in Equation (1). At the PEEK-WS 2 nanoparticle interface, thermal walkers from either the PEEK or the $\mathrm{WS}_{2}$ behave similarly to the walkers crossing the PEEK-SWNT interface from the PEEK side. However, the two probabilities $\left(f_{\mathrm{m}-\mathrm{WS}_{2}}\right.$ and $\left.f_{\mathrm{WS}_{2}-\mathrm{m}}\right)$ have different relation from that described in Equation (3), due to the different motion of walkers in $\mathrm{WS}_{2}$ nanoparticles and SWNTs. As thermal walkers have Brownian motion in $\mathrm{WS}_{2}$ nanoparticles, $f_{\mathrm{m}-\mathrm{WS}_{2}}$ and $f_{\mathrm{WS}_{2}-\mathrm{m}}$ are related as:

$$
f_{\mathrm{WS}_{2}-\mathrm{m}}=C_{f-\mathrm{WS}_{2}} \frac{\left(r+\sigma_{\mathrm{m}}\right)^{3}-r^{3}}{r^{3}-\left(-\sigma_{\mathrm{WS}_{2}}\right)^{3}} f_{\mathrm{m}-\mathrm{WS}_{2}}
$$


where $f_{\mathrm{WS}_{2}-\mathrm{m}}$ and $f_{\mathrm{m}-\mathrm{WS}}$ are the walker travelling probabilities from the $\mathrm{WS}_{2}$ nanoparticles to the PEEK matrix and the reverse. Variables $r, \sigma_{\mathrm{m}}$ and $\sigma_{\mathrm{WS}_{2}}$ are the radius of the $\mathrm{WS}_{2}$ nanoparticles, the standard deviation of Brownian motion in the PEEK matrix, and the standard deviation of Brownian motion in the $\mathrm{WS}_{2}$ nanoparticles, respectively. The parameter $C_{f-\mathrm{WS}_{2}}$ is the thermal equilibrium factor at the PEEK-WS ${ }_{2}$ nanoparticle interface, which can be numerically determined in the same manner as $C_{f-S W N T}$ [27-29]. Thermal walkers will be bounced back when they jump outside of the model to maintain a constant heat flux. Periodic boundary conditions are applied in the $\mathrm{y}$ and $\mathrm{z}$ directions.

The computational domain was divided into $300 \times 300 \times 300$ grids to calculate the temperature profile, which can be obtained by counting the number of hot walkers and then subtracting the number of cold walkers in a grid cell. Figure $1 \mathrm{~b}$ shows a typical contour plot of thermal walker distribution in the thermal steady state. With constant heat flux applied along the $x$ direction, the temperature along the $x$ direction should be a straight line which has a slope inversely proportional to the thermal conductivity of the SWNT/ $\mathrm{WS}_{2} /$ PEEK composite [30]. A reference model of pure PEEK matrix was also built to estimate the effective thermal conductivity $\left(K_{\text {eff }}\right)$ of the composite. With the same heat flux and boundary conditions, the temperature profiles along $\mathrm{x}$ direction in the composite model and the pure matrix model are related as:

$$
q^{\prime \prime}=-K_{\mathrm{eff}} \frac{d T_{\mathrm{c}}}{d x}=-K_{\mathrm{m}} \frac{d T_{\mathrm{m}}}{d x}
$$

where $q^{\prime \prime}, T_{\mathrm{c}}$ and $T_{\mathrm{m}}$ are the applied constant heat flux, the temperature in the composite and the temperature in the pure PEEK matrix, respectively. $K_{\mathrm{m}}$ is the thermal conductivity of the pure PEEK matrix, which is known to be $0.23 \mathrm{~W} / \mathrm{m} \cdot \mathrm{K}$ from the literature [31]. Thus, as expressed in Equation (5), the effective thermal conductivity of the composite $\left(K_{\text {eff }}\right)$ can be calculated based on the temperature profiles in the composite and the pure PEEK.

\section{Results and Discussion}

In this section, three case studies are presented and discussed to demonstrate the capabilities of the developed off-lattice Monte Carlo approach. The case study systems include three-phase SWNT $/ \mathrm{WS}_{2} /$ PEEK composites, SWNT/ $\mathrm{WS}_{2} /$ PEEK composites with SWNT bundles and graphene/PMMA composites with different sized graphene sheets. The typical parameters influencing or limiting the thermal transport properties of the composites were quantitatively investigated. The quantitative findings may provide an overview of the thermal transport phenomena and limitation mechanisms in multiphase composites.

\subsection{Model of Three-Phase SWNT/WS 2 /PEEK Composites}

\subsubsection{Validation of the Developed Off-Lattice Monte Carlo Approach}

The developed approach was validated by comparing the simulation results with the measured $K_{\text {eff }}$ of SWNT/WS $/$ PEEK composites with different compositions [9], as presented in Figure 2. The different compositions (e.g., 0.5/0.5/99.0) were marked with the mass fractions of the SWNTs $(0.5 \%)$, the $\mathrm{WS}_{2}$ nanoparticles $(0.5 \%)$ and the PEEK matrix $(99.0 \%)$. In the models for different compositions, the dimensions of the SWNTs and the diameter of the $\mathrm{WS}_{2}$ nanoparticle were maintained, while the side length of the PEEK cube was varied. As shown in Figure 2, the simulation results from our approach are in good agreement with the experimental data, which validates the developed approach. 


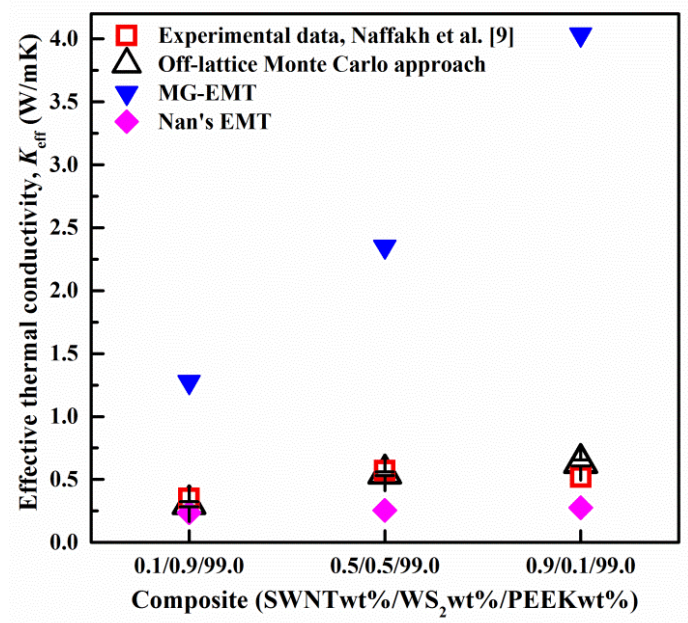

Figure 2. Validation of the developed approach by comparing the simulation results with the experimental data from Reference [9]. The side lengths of the PEEK cubes in 0.1/0.9/99.0, 0.5/0.5/99.0 and 0.9/0.1/99.0 compositions were 760, 925 and $1580 \mathrm{~nm}$, respectively. The interfacial thermal resistance at SWNT-PEEK interface was used as $1.0 \times 10^{-8} \mathrm{~m}^{2} \cdot \mathrm{K} / \mathrm{W}$ for Nan et al.'s effective medium theory (EMT) [32]. The error bars represent the standard deviation of the results obtained from 3 separate simulations with different distribution of SWNTs. Reproduced with permission from [18]. Copyright Elsevier, 2014.

Effective medium theory approaches (EMT) are commonly applied to predict the $K_{\text {eff }}$ of composites [33-36]. For comparison with our developed approach, two widely-used EMTs (i.e., the Maxwell-Garnett model (MG) [35,37] and Nan et al.'s model [38]) were utilized to predict the $K_{\text {eff }}$ of the SWNT $/ \mathrm{WS}_{2} /$ PEEK composites. The comparison among different models is presented in Figure 2. The MG-EMT overestimated the $K_{\text {eff }}$ of the SWNT/WS $/$ /PEEK composites, which is likely due to the neglect of the interfacial thermal resistance at the SWNT-PEEK interface. On the contrary, Nan et al.'s EMT model underestimated the $K_{\text {eff }}$ of the $S W N T / W_{2} /$ PEEK composites. This is because that model does not account for the synergistic effects of SWNTs and $\mathrm{WS}_{2}$ nanoparticles in the composites.

\subsubsection{Effects of Interfacial Thermal Resistances on the $K_{\text {eff }}$ of SWNT/WS $/$ PEEK Composites}

The interfacial thermal resistance $\left(R_{\mathrm{bd}}\right)$ at the nanofiller-matrix interface (i.e., SWNT-PEEK, $\mathrm{WS}_{2}$-PEEK) is caused by the difference in the vibrational phonon spectra of each side, and by interfacial defects $[39,40]$. The $R_{\mathrm{bd}}$ is found to greatly limit the $K_{\text {eff }}$ of SWNT $/ \mathrm{WS}_{2} / \mathrm{PEEK}$ composites [10]. The $R_{\mathrm{bd}}$ at the SWNT-PEEK ( $R_{\mathrm{SWNT}}$-PEEK $)$ and $\mathrm{WS}_{2}$-PEEK $\left(R_{\mathrm{WS}_{2}-\mathrm{PEEK}}\right)$ interfaces was varied to investigate the effects on the $K_{\text {eff }}$ of $S W N T / W_{2} /$ PEEK composites, and the results are presented in Figure 3 . The $R_{\mathrm{bd}}$ is interpreted by an average phonon transmission probability at the interfaces in our approach, as described already above. It has been reported in the literature that the $R_{\mathrm{bd}}$ in the nanoscale falls into the range of $1.0 \times 10^{-9}-1.0 \times 10^{-6} \mathrm{~m}^{2} \cdot \mathrm{K} / \mathrm{W}$ [41-44], so the $R_{\text {SWNT-PEEK }}$ was varied between $1.158 \times 10^{-9}$ and $1.158 \times 10^{-6} \mathrm{~m}^{2} \cdot \mathrm{K} / \mathrm{W}$, which corresponds to an average phonon transmission probability of 0.001-1.0. Similarly, the $R_{\mathrm{WS}_{2}-\mathrm{PEEK}}$ ranged from $2.32 \times 10^{-10}$ to $2.32 \times 10^{-8} \mathrm{~m}^{2} \cdot \mathrm{K} / \mathrm{W}$, corresponding to an average phonon transmission probability from 0.005 to 0.5 . 

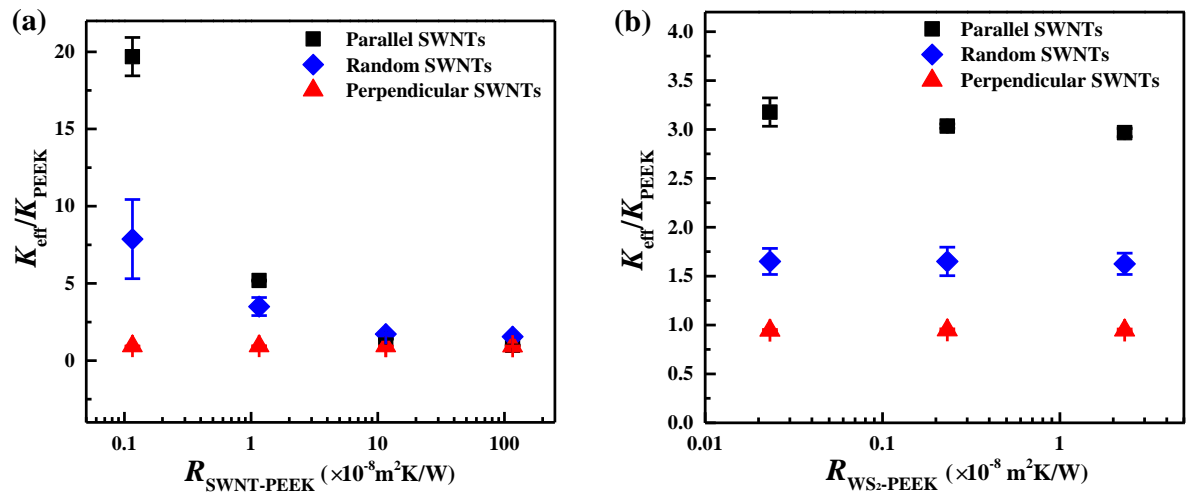

Figure 3. Effects of the interfacial thermal resistances at (a) SWNT-PEEK and (b) $\mathrm{WS}_{2}$-PEEK interfaces on the $K_{\text {eff }}$ of SWNT/WS $/$ PEEK composites. The 0.5/0.5/99.0 composition was used for this quantitative study. The models with different SWNT orientation (e.g., SWNTs parallel to the heat flux, SWNTs randomly orientated to the heat flux, and SWNTs perpendicular to the heat flux) were built to study the effect of SWNT orientations. The error bars represent the standard deviation of the results from 3 separate simulations with different distribution of SWNTs. Reproduced with permission from [18]. Copyright Elsevier, 2014.

As shown in Figure 3 , the $K_{\text {eff }}$ of $S W N T / W_{2} /$ PEEK composites decreases with both $R_{\text {SWNT-PEEK }}$ and $R_{\mathrm{WS}_{2}-\mathrm{PEEK}}$. In Figure $3 \mathrm{~b}$, compared with that in the parallel SWNT case, the effect of $R_{\mathrm{WS}_{2}-\mathrm{PEEK}}$ on the $K_{\text {eff }}$ of SWNT/WS $/$ /PEEK composites is much weaker in the random and perpendicular SWNT

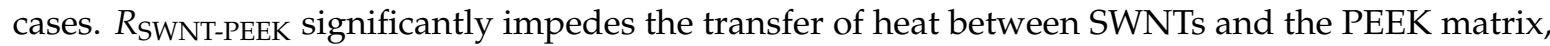
weakening the enhancement of SWNTs on the $K_{\text {eff }}$. At a high $R_{\text {SWNT-PEEK, }}$ SWNTs with three different orientations lead to a similar $K_{\text {eff }}$, which is close to the $K_{\mathrm{PEEK}}$, indicating that SWNTs do not enhance

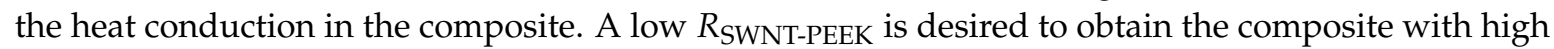
$K_{\text {eff }}$, which may be achieved by proper functionalization of SWNTs to couple the phonon spectra of SWNTs and PEEK [45-47]. The influence of $R_{W_{2}}$-PEEK on the $K_{\text {eff }}$ of composites is much weaker than

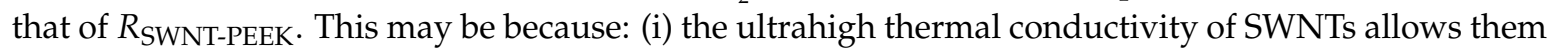
to dominate the heat transfer through composites; (ii) the much larger interfacial area of SWNTs make the influence of the SWNT-PEEK interface more significant than that of the $\mathrm{WS}_{2}$-PEEK interface for heat transfer; (iii) the long cylindrical SWNTs are more effective than the spherical $\mathrm{WS}_{2}$ nanoparticles to enhance the $K_{\text {eff }}$ of the composites [48], offering a larger characteristic length scale over which heat can be transferred.

\subsubsection{Effects of the Morphology of SWNTs on the $K_{\text {eff }}$ of SWNT/ $\mathrm{WS}_{2} / \mathrm{PEEK}$ Composites}

Since SWNTs dominate the heat transfer in the three-phase composites, the morphology of SWNTs (i.e., length and diameter) was varied to study its effect on the $K_{\text {eff }}$ of $S W N T / W_{2} /$ PEEK composites. The length was varied from 100 to $900 \mathrm{~nm}$ while keeping a constant diameter of $2 \mathrm{~nm}$. The diameter was varied from 2 to $8 \mathrm{~nm}$ while the length was kept at $500 \mathrm{~nm}$. As presented in Figure 4, when SWNTs are parallel or random to the heat flux, longer SWNTs induce higher $K_{\text {eff }}$, which is consistent with previous studies [39,49]. Due to the ballistic phonon transport in SWNTs, longer SWNTs are more effective than short ones to transport heat through the composites, leading to a higher $K_{\text {eff }}$ [50]. For the study of SWNT diameter, a composite with randomly oriented SWNTs was chosen for investigation as it represents most realistic composites. As shown in Figure $4 \mathrm{~b}$, the $K_{\text {eff }}$ of SWNT/WS $2 /$ PEEK composites increases with the decrease of SWNT diameter, which may be ascribed to the interfacial area of SWNTs. With same volume fraction of SWNTs, a larger interfacial area between SWNTs and PEEK is obtained for SWNTs having smaller diameter. The larger interfacial area can afford more effective heat transfer channels between SWNTs and PEEK, thus inducing a larger enhancement of the $K_{\text {eff. }}$ The diameter used here covers the range of SWNTs $(\leqslant 2 \mathrm{~nm})$, double-walled CNTs $(2-4 \mathrm{~nm})$, 
and multi-walled CNTs $(\geqslant 4 \mathrm{~nm})$. Therefore, it can be speculated that SWNTs are more efficient than other CNTs to enhance the $K_{\text {eff }}$ of SWNT/WS $2 /$ PEEK composites.
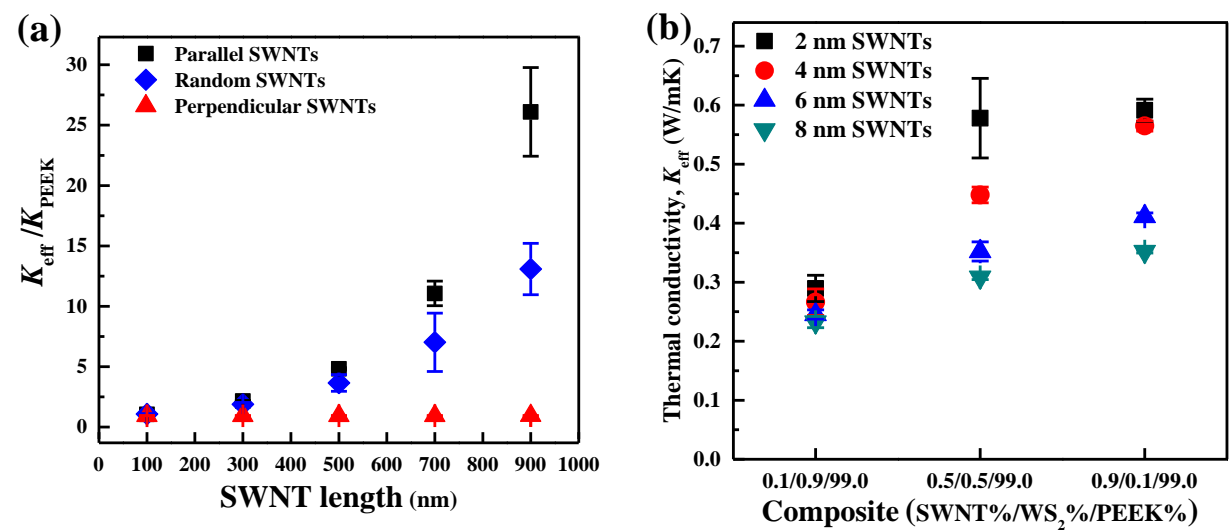

Figure 4. Effects of (a) length and (b) diameter of SWNTs on the $K_{\mathrm{eff}}$ of SWNT/WS $2 / \mathrm{PEEK}$ composites. The length was varied from 100 to $900 \mathrm{~nm}$, corresponding to an aspect ratio from 50 to 450 . The diameter was varied from 2 to $8 \mathrm{~nm}$ while the length was kept as $500 \mathrm{~nm}$. Different compositions with randomly orientated SWNTs were chosen to study the effect of SWNT diameter. The error bars represent the standard deviation of the results obtained from 3 separate simulations with different distribution of SWNTs. Reproduced with permission from [18]. Copyright Elsevier, 2014.

\subsection{Model of SWNT/WS 2 /PEEK Composites with SWNT Bundles}

SWNTs tend to aggregate into bundles during the composite synthesis process due to strong van der Waals forces. The thermal conductivity of SWNT bundles is generally lower than that of an individual SWNT in the bundle, due to the interfacial thermal resistance among adjacent SWNTs [51-53]. Thus, the SWNT bundles may limit heat transfer in the composites [39]. A SWNT/WS $/$ /PEEK composite model with SWNT bundles was built to shed some light on the influence of SWNT bundles on the thermal transport properties of the composites. As shown in Figure 5, there were individual SWNTs, SWNT bundles, $W_{2}$ nanoparticles, and PEEK matrix in the system. In the present work, only the straight bundles with line contacts were taken into account. The CNT bundles with complicated interconnected networks were out of the scope of this article.

(a)

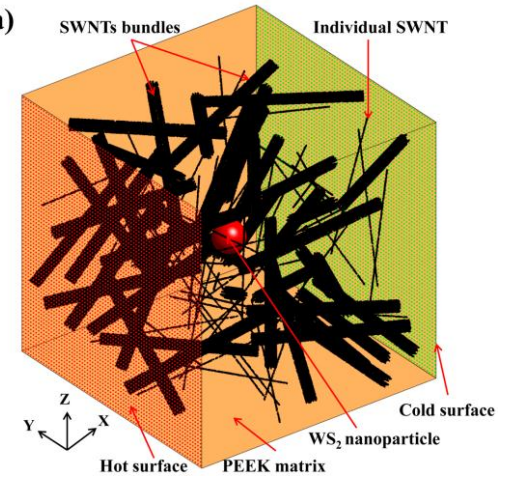

(b)

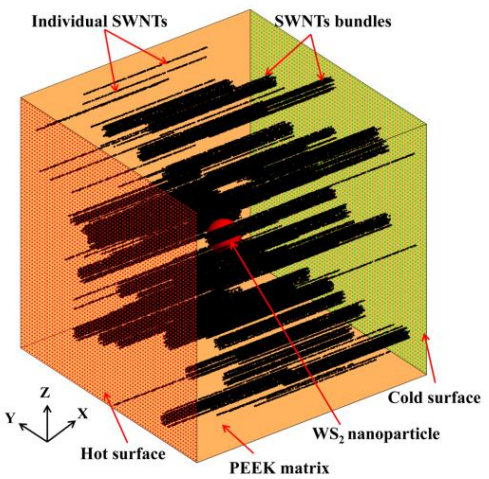

Figure 5. Schematic plot of the SWNT/WS $/$ PEEK model with SWNT bundles: (a) $\mathrm{A} \mathrm{WS}_{2}$ nanoparticle (painted red) with $110 \mathrm{~nm}$ diameter is located in the center of a PEEK cube $\left(925 \times 925 \times 925 \mathrm{~nm}^{3}\right)$. A total of 960 SWNTs ( $2 \mathrm{~nm}$ diameter and $500 \mathrm{~nm}$ length, painted black) are randomly dispersed in the model, forming 45 bundles with 20 SWNTs in each bundle and 60 unbundled SWNTs. Constant heat flux is applied along $\times$ direction; (b) composite with individual SWNTs and SWNT bundles oriented parallel to the heat-flux direction. Reproduced with permission from [24]. Copyright American Chemical Society, 2015. 


\subsubsection{Effects of the Morphology of SWNT Bundles on the $K_{\text {eff }}$ of SWNT/WS $2 / P E E K$ Composites}

The number of SWNT bundles was changed from 0 to 48 (no individual SWNTs) to investigate the effect of SWNT dispersion state on the $K_{\text {eff }}$ of the SWNT/WS $2 /$ PEEK composites, and the results are presented in Figure 6a. The models with different SWNT orientations (parallel, random and perpendicular to the heat flux) were all built, as illustrated in Figure 5. As shown in Figure 6a, when SWNT bundles are parallel or randomly oriented relative to the direction of the heat flux, the $K_{\text {eff }}$ of the composites slightly decreases with an increase of SWNT bundles. This may be caused by the non-uniform distribution of SWNTs with the presence of SWNT bundles, as well as the SWNT-SWNT thermal resistance within the bundles, which prevents heat from conducting along the heat flux direction [54]. Different from the above two SWNT orientations, more SWNT bundles perpendicular to the heat flux can induce a higher $K_{\text {eff }}$ of the SWNT/WS $/$ PEEK composites. The $K_{\text {eff }}$ slightly increases by $40 \%$ when the bundle number increases to 48 . This is likely due to the bigger diameter of SWNT bundles compared with individual SWNTs, which accelerates the heat transfer in the radial direction (also the heat flux direction).

The number of individual SWNTs in each bundle was varied from 10 to 25, at an increment of 5 , to study its influence on the $K_{\text {eff }}$ of the composites. The total number of SWNTs (960) and the number of SWNT bundles (36) were kept constant. As shown in Figure 5b, when SWNT bundles are parallel or randomly oriented relative to the heat flux, more SWNTs in each bundle induce a lower $K_{\text {eff }}$. With the same number of bundles, more SWNTs per bundle lead to a worse distribution of SWNTs, which may reduce the heat transfer along the heat flux. On the other hand, more SWNTs in a bundle increase the stiffness of the bundle, which weakens the phonon coupling between SWNTs and PEEK via low-frequency vibrations [55], thus leading to a larger SWNT-PEEK thermal resistance [56]. When SWNT bundles are perpendicular to the heat flux, the number of SWNTs in each bundle has no apparent effect on the $K_{\text {eff }}$ of the composites.
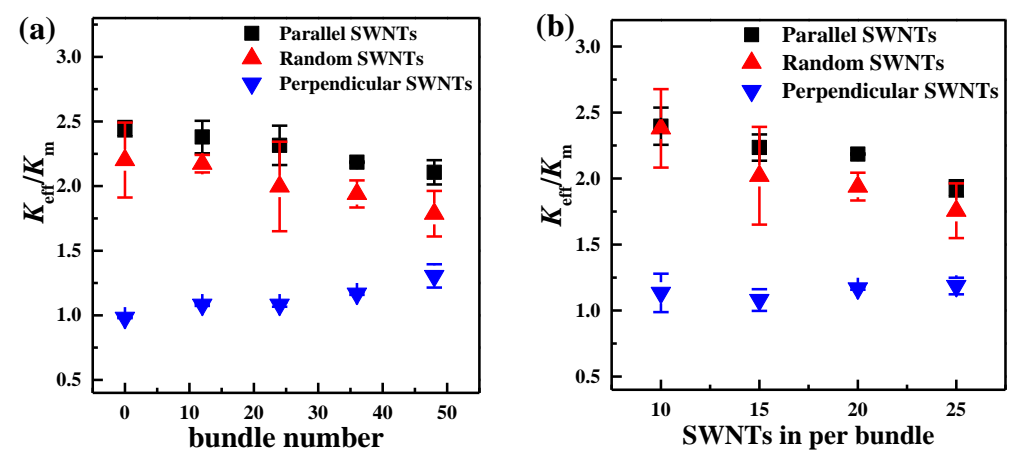

Figure 6. Effects of the morphology of SWNT bundles on the $K_{\text {eff }}$ of the SWNT/WS $2 /$ PEEK composites: (a) bundle number; and (b) the number of individual SWNTs in per bundle. The results for SWNTs with different orientations (parallel, random and perpendicular to the heat flux direction) are all presented. The error bars represent the standard deviation of the results obtained from 3 separate simulations with different distribution of SWNTs and SWNT bundles. Reproduced with permission from [24]. Copyright American Chemical Society, 2015.

\subsubsection{Effects of the SWNT-SWNT Thermal Resistance on the $K_{\text {eff }}$ of SWNT/WS $2 / P E E K$ Composites}

When SWNTs aggregate into bundle structures, SWNT-SWNT thermal resistance $\left(R_{\text {SWNT-SWNT }}\right)$ will exist among SWNTs within the bundles. Previous models cannot take into account this resistance for $K_{\text {eff }}$ prediction, whereas the developed approach can investigate this resistance by controlling the motion of thermal walkers at the SWNT-SWNT interface [24]. The $R_{\text {SWNT-SWNT was varied }}$ from $6.153 \times 10^{-10}$ to $6.153 \times 10^{-7} \mathrm{~m}^{2} \cdot \mathrm{K} / \mathrm{W}$, corresponding to an average phonon transmission probability of $0.001-1.0$ [57]. As presented in Figure 7, the $K_{\text {eff }}$ of the SWNT/WS $2 / P E E K$ composites 
decreases with the increase of the $R_{\mathrm{SWNT} \text {-SWNT }}$. A higher $R_{\mathrm{SWNT}} \mathrm{SWNT}$ more greatly prevents heat from transferring among the bundled SWNTs, leading to a lower $K_{\text {eff }}$ of the composites.

A critical SWNT-SWNT thermal resistance, $R_{c}$, was found to dominate the heat transfer in the composites, which was estimated to be $0.155 \times 10^{-8} \mathrm{~m}^{2} \cdot \mathrm{K} / \mathrm{W}$. When $R_{\mathrm{SWNT}}$-SWNT $<R_{c}$, more SWNT bundles may induce a higher $K_{\text {eff }}$ of the composite. This is because at low $R_{\text {SWNT-SWNT }}$, heat prefers to transfer through SWNT-SWNT contacts, thus the SWNT bundles would be more effective heat transfer channels than the mono-dispersed SWNTs. It can be inferred that the detrimental effect of the SWNT bundles could be reduced by decreasing the $R_{\text {SWNT-SWNT }}$ to be less than $R_{c}$, which may be achieved by covalent functionalization to enhance the phonon coupling and weaken the phonon scattering at a SWNT-SWNT interface $[58,59]$.

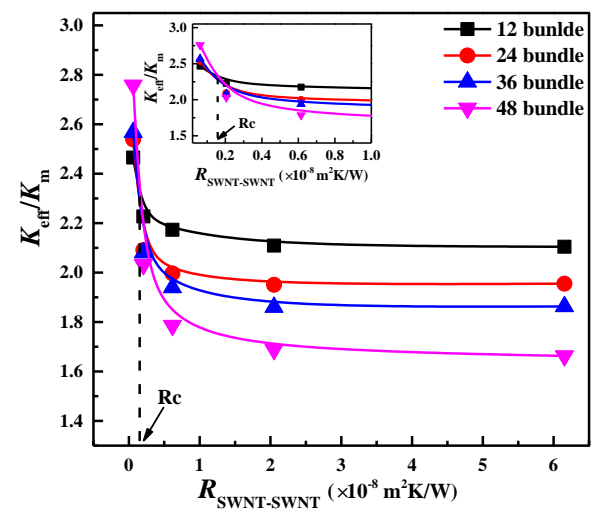

Figure 7. Effect of the SWNT-SWNT thermal resistance on the $K_{\text {eff }}$ of the SWNT/WS $2 / P E E K$ composites with 12-48 SWNT bundles. The SWNTs were randomly distributed in the composites. The individual SWNT number in each bundle was kept at 20. The critical TBR (dashed line) was estimated to be $R_{\mathrm{C}}=0.155 \times 10^{-8} \mathrm{~m}^{2} \cdot \mathrm{K} / \mathrm{W}$ by intersecting the $K_{\text {eff }}$ curves of different SWNT bundles, as shown in the insert figure. Reproduced with permission from [24]. Copyright American Chemical Society, 2015.

\subsection{Model of Graphene/PMMA with Complex Structure}

In the graphene-based polymer composites, graphene sheets have a large size distribution in the $x-y$ plane $(50-500 \mathrm{~nm})$ due to the oxidation and reduction of graphene sheets during the composite fabrication [3]. The existing models commonly ignore the size distribution of graphene sheets, resulting in an inaccurate prediction of the thermal conductivity. In the developed approach, one can take into account the size distribution (various length, width and thickness), volume fraction and orientation of graphene sheets, as well as the interfacial thermal resistance at the graphene-polymer interface.

In this subsection, a graphene/PMMA composite model was built to validate that the develop approach can be applied to study graphene/polymer composites. Graphene sheets with various length $(50-500 \mathrm{~nm})$, width $(50-500 \mathrm{~nm})$, thickness $(2.4-9.0 \mathrm{~nm})$ and different orientations (parallel, random and perpendicular to the heat flux) were generated in the model.

The developed graphene/PMMA model was validated by comparing the predicted $K_{\text {eff }}$ with the measured results, as shown in Figure 8a. As the interfacial thermal resistance $\left(R_{\mathrm{bd}}\right)$ at the graphene-PMMA interface was an input value, the model was validated as follows: Estimate the $R_{\text {bd }}$ by matching the simulated $K_{\text {eff }}$ with the measured value for one composite, and then use this estimated $R_{\mathrm{bd}}$ as input to calculate the $K_{\text {eff }}$ of other composites. The predicted $K_{\text {eff }}$ showed a good agreement with the experimental data, validating the developed model. The $R_{\mathrm{bd}}$ was estimated to be $1.906 \times 10^{-8} \mathrm{~m}^{2} \cdot \mathrm{K} / \mathrm{W}$. For comparison, a modified effective medium theory (EMT) was used to calculate the $K_{\text {eff }}$ of the graphene/PMMA composites, and the results are presented in Figure $8 \mathrm{~b}$. The estimated $K_{\text {eff }}$ from the modified EMT is much higher than the experimental results, and even higher than the predicted $K_{\text {eff }}$ of the model with parallel graphene. This is likely because the modified EMT cannot take into account the size distribution of graphene sheets. In the modified EMT, the length 
and width were treated as infinite when compared with the thickness of graphene sheets, which failed to take into account the graphene sheet with relatively short length and width (e.g., $~ 50 \mathrm{~nm}$ ) [60-62]. It should be noted that if given the $K_{\text {eff }}$ of a specific composite, the interfacial thermal resistance between the nanofillers and the matrix can be estimated by using the developed approach and an inverse calculation procedure.
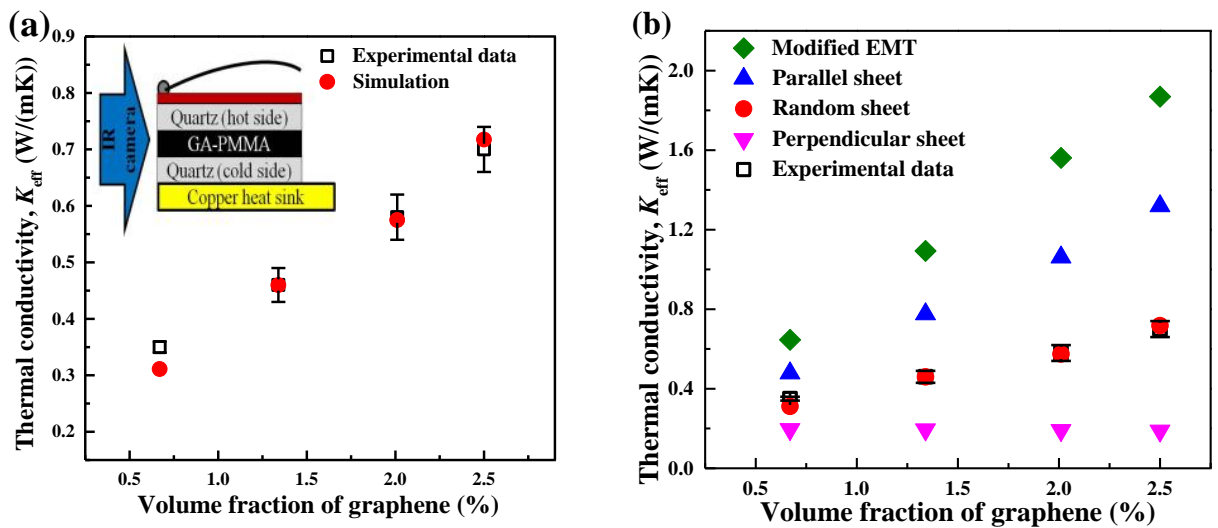

Figure 8. (a) Validation of the developed graphene/PMMA model by comparing the simulation results with the experimental data for different volume fractions of graphene sheets $(0.67 \%, 1.34 \%$, $2.01 \%$ and $2.50 \%$ ). The insert figure is the set-up scheme of the comparative infrared microscopy technique for measuring the thermal conductivity. More details of the experimental set-up can be found in Reference [4]; (b) the thermal conductivity of GA-PMMA composites as a function of graphene volume fraction. The interfacial thermal resistance between graphene sheets and PMMA was estimated to be $R_{\mathrm{bd}}=1.906 \times 10^{-8} \mathrm{~m}^{2} \cdot \mathrm{K} / \mathrm{W}$ in the developed model. The same value was utilized in the composites with parallel- and perpendicular-oriented graphene. In the modified EMT, the utilized thermal conductivity of graphene and the $R_{\mathrm{bd}}$ of graphene-PMMA were $100 \mathrm{~W} / \mathrm{m} \cdot \mathrm{K}$ and $1.0 \times 10^{-8} \mathrm{~m}^{2} \cdot \mathrm{K} / \mathrm{W}$, respectively. The error bars represent the standard deviation of the results from separate measurements of thermal conductivity of graphene/PMMA composites. Reproduced with permission from [4]. Copyright Elsevier, 2015.

\section{Conclusions}

In summary, the developed off-lattice Monte Carlo approach has proved to be accurate as a computational model for heat transfer phenomena and heat transfer mechanisms for multiphase composites with complex structures. The developed approach not only provides a more accurate method to predict the $K_{\text {eff }}$ of the multiphase composites than existing EMT models, but also offers an effective computational approach to estimate the interfacial thermal resistance between the nanofillers and the matrix. The quantitative findings presented herein showed that multiphase composites with higher $K_{\text {eff }}$ can be obtained by (a) reducing the interfacial thermal resistances at filler-matrix interfaces; (b) aligning the fillers along the heat flux direction; (c) using fillers with larger interfacial area; and (d) improving the dispersion of fillers to be more uniform rather than forming bundles. Through proper modifications of the geometry and thermal properties of the components in the model, the developed approach may be applied to study the thermal transport properties of other multiphase systems, such as CNT/graphene/polymer composites, graphene stabilized polymer blends, CNT stabilized emulsions and other multiphase organic or inorganic composites.

Acknowledgments: Part of this work was done while Dimitrios V. Papavassiliou was serving at the National Science Foundation (NSF). Any opinion, findings, and conclusions or recommendations expressed in this material are those of the authors and do not necessarily reflect the views of the NSF.

Conflicts of Interest: The authors declare no conflict of interest. 


\section{References}

1. Thakur, V.K.; Thakur, M.K.; Raghavan, P.; Kessler, M.R. Progress in green polymer composites from lignin for multifunctional applications: A review. ACS Sustain. Chem. Eng. 2014, 2, 1072-1092. [CrossRef]

2. De Volder, M.F.L.; Tawfick, S.H.; Baughman, R.H.; Hart, A.J. Carbon nanotubes: Present and future commercial applications. Science 2013, 339, 535-539. [CrossRef] [PubMed]

3. Shahil, K.M.F.; Balandin, A.A. Graphene-multilayer graphene nanocomposites as highly efficient thermal interface materials. Nano Lett. 2012, 12, 861-867. [CrossRef] [PubMed]

4. Fan, Z.; Gong, F.; Nguyen, S.T.; Duong, H.M. Advanced multifunctional graphene aerogel—Poly(methyl methacrylate) composites: Experiments and modeling. Carbon 2015, 81, 396-404. [CrossRef]

5. Dai, W.; Yu, J.; Liu, Z.; Wang, Y.; Song, Y.; Lyu, J.; Bai, H.; Nishimura, K.; Jiang, N. Enhanced thermal conductivity and retained electrical insulation for polyimide composites with sic nanowires grown on graphene hybrid fillers. Compos. Part A 2015, 76, 73-81. [CrossRef]

6. Yan, Z.; Nika, D.L.; Balandin, A.A. Thermal properties of graphene and few-layer graphene: Applications in electronics. Inst. Eng. Technol. 2015, 9, 4-12. [CrossRef]

7. Qian, R.; Yu, J.; Wu, C.; Zhai, X.; Jiang, P. Alumina-coated graphene sheet hybrids for electrically insulating polymer composites with high thermal conductivity. RSC Adv. 2013, 3, 17373-17379. [CrossRef]

8. Zhao, Y.-H.; Zhang, Y.-F.; Bai, S.-L. High thermal conductivity of flexible polymer composites due to synergistic effect of multilayer graphene flakes and graphene foam. Compos. Part A 2016, 85, 148-155. [CrossRef]

9. Naffakh, M.; Diez-Pascual, A.M.; Gomez-Fatou, M.A. New hybrid nanocomposites containing carbon nanotubes, inorganic fullerene-like $\mathrm{WS}_{2}$ nanoparticles and poly(ether ether ketone) (PEEK). J. Mater. Chem. 2011, 21, 7425-7433. [CrossRef]

10. Naffakh, M.; Diez-Pascual, A.M.; Marco, C.; Ellis, G. Morphology and thermal properties of novel poly(phenylene sulfide) hybrid nanocomposites based on single-walled carbon nanotubes and inorganic fullerene-like $\mathrm{WS}_{2}$ nanoparticles. J. Mater. Chem. 2012, 22, 1418-1425. [CrossRef]

11. Im, H.; Kim, J. Thermal conductivity of a graphene oxide-carbon nanotube hybrid/epoxy composite. Carbon 2012, 50, 5429-5440. [CrossRef]

12. Gupta, T.K.; Singh, B.P.; Mathur, R.B.; Dhakate, S.R. Multi-walled carbon nanotube-graphene-polyaniline multiphase nanocomposite with superior electromagnetic shielding effectiveness. Nanoscale 2014, 6, 842-851. [CrossRef] [PubMed]

13. Yu, L.; Park, J.S.; Lim, Y.-S.; Lee, C.S.; Shin, K.; Moon, H.J.; Yang, C.-M.; Lee, Y.S.; Han, J.H. Carbon hybrid fillers composed of carbon nanotubes directly grown on graphene nanoplatelets for effective thermal conductivity in epoxy composites. Nanotechnology 2013, 24. [CrossRef] [PubMed]

14. Gao, Z.; Zhao, L. Effect of nano-fillers on the thermal conductivity of epoxy composites with micro- $\mathrm{Al}_{2} \mathrm{O}_{3}$ particles. Mater. Des. 2015, 66, 176-182. [CrossRef]

15. Luan, V.H.; Tien, H.N.; Cuong, T.V.; Kong, B.-S.; Chung, J.S.; Kim, E.J.; Hur, S.H. Novel conductive epoxy composites composed of 2-D chemically reduced graphene and 1-D silver nanowire hybrid fillers. J. Mater. Chem. 2012, 22, 8649-8653. [CrossRef]

16. Cheng, H.K.F.; Basu, T.; Sahoo, N.G.; Li, L.; Chan, S.H. Current advances in the carbon nanotube/thermotropic main-chain liquid crystalline polymer nanocomposites and their blends. Polymers 2012, 4, 889-912. [CrossRef]

17. Wang, F.; Drzal, L.T.; Qin, Y.; Huang, Z. Enhancement of fracture toughness, mechanical and thermal properties of rubber/epoxy composites by incorporation of graphene nanoplatelets. Compos. Part A 2016, 87, 10-22. [CrossRef]

18. Gong, F.; Bui, K.; Papavassiliou, D.V.; Duong, H.M. Thermal transport phenomena and limitations in heterogeneous polymer composites containing carbon nanotubes and inorganic nanoparticles. Carbon 2014, 78, 305-316. [CrossRef]

19. Duong, H.M.; Papavassiliou, D.V.; Lee, L.L.; Mullen, K.J. Random walks in nanotube composites: Improved algorithms and the role of thermal boundary resistance. Appl. Phys. Lett. 2005, 87. [CrossRef]

20. Voronov, R.S.; VanGordon, S.B.; Sikavitsas, V.I.; Papavassiliou, D.V. Efficient lagrangian scalar tracking method for reactive local mass transport simulation through porous media. Int. J. Numer. Methods Fluids 2011, 67, 501-517. [CrossRef] 
21. Tomadakis, M.M.; Sotirchos, S.V. Transport properties of random arrays of freely overlapping cylinders with various orientation distributions. J. Chem. Phys. 1993, 98, 616-626. [CrossRef]

22. Papavassiliou, D.V. Turbulent transport from continuous sources at the wall of a channel. Int. J. Heat Mass Transf. 2002, 45, 3571-3583. [CrossRef]

23. Mitrovic, B.M.; Le, P.M.; Papavassiliou, D.V. On the prandtl or schmidt number dependence of the turbulent heat or mass transfer coefficient. Chem. Eng. Sci. 2004, 59, 543-555. [CrossRef]

24. Gong, F.; Duong, H.M.; Papavassiliou, D.V. Inter-carbon nanotube contact and thermal resistances in heat transport of three-phase composites. J. Phys. Chem. C 2015, 119, 7614-7620. [CrossRef]

25. Einstein, A. The electrodynamics of moving bodies. Ann. Phys. 1905, 17, 891-921. [CrossRef]

26. Swartz, E.T.; Pohl, R.O. Thermal-boundary resistance. Rev. Mod. Phys. 1989, 61, 605-668. [CrossRef]

27. Gong, F.; Papavassiliou, D.V.; Duong, H.M. Off-lattice monte carlo simulation of heat transfer through carbon nanotube multiphase systems taking into account thermal boundary resistances. Numer. Heat Transf. Part $A$ 2014, 65, 1023-1043. [CrossRef]

28. Duong, H.M.; Yamamoto, N.; Papavassiliou, D.V.; Maruyama, S.; Wardle, B.L. Inter-carbon nanotube contact in thermal transport of controlled-morphology polymer nanocomposites. Nanotechnology 2009, 20. [CrossRef] [PubMed]

29. Gong, F.; Hongyan, Z.; Papavassiliou, D.V.; Bui, K.; Lim, C.; Duong, H.M. Mesoscopic modeling of cancer photothermal therapy using single-walled carbon nanotubes and near infrared radiation: Insights through an off-lattice monte carlo approach. Nanotechnology 2014, 25. [CrossRef] [PubMed]

30. Bird, R.B.; Stewart, W.E.; Lightfoot, E.N. Transport Phenomena, 2nd ed.; John Wiley \& Sons: New York, NY, USA, 2007.

31. Diez-Pascual, A.M.; Naffakh, M.; Marco, C.; Ellis, G.; Gomez-Fatou, M.A. High-performance nanocomposites based on polyetherketones. Prog. Mater. Sci. 2012, 57, 1106-1190. [CrossRef]

32. Hida, S.; Hori, T.; Shiga, T.; Elliott, J.; Shiomi, J. Thermal resistance and phonon scattering at the interface between carbon nanotube and amorphous polyethylene. Int. J. Heat Mass Transf. 2013, 67, 1024-1029. [CrossRef]

33. Haggenmueller, R.; Guthy, C.; Lukes, J.R.; Fischer, J.E.; Winey, K.I. Single wall carbon nanotube/polyethylene nanocomposites: Thermal and electrical conductivity. Macromolecules 2007, 40, 2417-2421. [CrossRef]

34. Jiang, W.T.; Ding, G.L.; Peng, H. Measurement and model on thermal conductivities of carbon nanotube nanorefrigerants. Int. J. Therm. Sci. 2009, 48, 1108-1115. [CrossRef]

35. Nan, C.W.; Shi, Z.; Lin, Y. A simple model for thermal conductivity of carbon nanotube-based composites. Chem. Phys. Lett. 2003, 375, 666-669. [CrossRef]

36. Xue, Q.Z. Model for the enective thermal conductivity of carbon nanotube composites. Nanotechnology 2006, 17, 1655-1660. [CrossRef] [PubMed]

37. Choi, S.U.S.; Zhang, Z.G.; Yu, W.; Lockwood, F.E.; Grulke, E.A. Anomalous thermal conductivity enhancement in nanotube suspensions. Appl. Phys. Lett. 2001, 79, 2252-2254. [CrossRef]

38. Nan, C.W.; Liu, G.; Lin, Y.H.; Li, M. Interface effect on thermal conductivity of carbon nanotube composites. Appl. Phys. Lett. 2004, 85, 3549-3551. [CrossRef]

39. Han, Z.D.; Fina, A. Thermal conductivity of carbon nanotubes and their polymer nanocomposites: A review. Prog. Polym. Sci. 2011, 36, 914-944. [CrossRef]

40. Shenogin, S. Role of thermal boundary resistance on the heat flow in carbon-nanotube composites. J. Appl. Phys. 2004, 95. [CrossRef]

41. Konatham, D.; Striolo, A. Thermal boundary resistance at the graphene-oil interface. Appl. Phys. Lett. 2009, 95. [CrossRef]

42. Maruyama, S.; Igarashi, Y.; Taniguchi, Y.; Shiomi, J. Anisotropic heat transfer of single-walled carbon nanotubes. J. Therm. Sci. Technol. 2006, 1, 138-148. [CrossRef]

43. Huxtable, S.T.; Cahill, D.G.; Shenogin, S.; Xue, L.P.; Ozisik, R.; Barone, P.; Usrey, M.; Strano, M.S.; Siddons, G.; Shim, M.; et al. Interfacial heat flow in carbon nanotube suspensions. Nat. Mater. 2003, 2, 731-734. [CrossRef] [PubMed]

44. Shukla, N.C.; Liao, H.H.; Abiade, J.T.; Liu, F.X.; Liaw, P.K.; Huxtable, S.T. Thermal conductivity and interface thermal conductance of amorphous and crystalline $\mathrm{Zr}_{47} \mathrm{Cu}_{31} \mathrm{Al}_{13} \mathrm{Ni}_{9}$ alloys with a $\mathrm{Y}_{2} \mathrm{O}_{3}$ coating. Appl. Phys. Lett. 2009, 94. [CrossRef] 
45. Shenogin, S.; Bodapati, A.; Xue, L.; Ozisik, R.; Keblinski, P. Effect of chemical functionalization on thermal transport of carbon nanotube composites. Appl. Phys. Lett. 2004, 85, 2229-2231. [CrossRef]

46. Clancy, T.C.; Gates, T.S. Modeling of interfacial modification effects on thermal conductivity of carbon nanotube composites. Polymer 2006, 47, 5990-5996. [CrossRef]

47. Lin, S.C.; Buehler, M.J. The effect of non-covalent functionalization on the thermal conductance of graphene/organic interfaces. Nanotechnology 2013, 24. [CrossRef] [PubMed]

48. Cherkasova, A.S.; Shan, J.W. Particle aspect-ratio effects on the thermal conductivity of micro- and nanoparticle suspensions. J. Heat Transf. Trans. ASME 2008, 130. [CrossRef]

49. Kapadia, R.S.; Louie, B.M.; Bandaru, P.R. The influence of carbon nanotube aspect ratio on thermal conductivity enhancement in nanotube-polymer composites. J. Heat Transf.Trans. ASME 2014, 136. [CrossRef]

50. Cherkasova, A.S.; Shan, J.W. Particle aspect-ratio and agglomeration-state effects on the effective thermal conductivity of aqueous suspensions of multiwalled carbon nanotubes. J. Heat Transf. Trans. ASME 2010, 132. [CrossRef]

51. Kim, P.; Shi, L.; Majumdar, A.; McEuen, P.L. Thermal transport measurements of individual multiwalled nanotubes. Phys. Rev. Lett. 2001, 87. [CrossRef] [PubMed]

52. Prasher, R. Thermal boundary resistance and thermal conductivity of multiwalled carbon nanotubes. Phys. Rev. B 2008, 77. [CrossRef]

53. Volkov, A.N.; Zhigilei, L.V. Scaling laws and mesoscopic modeling of thermal conductivity in carbon nanotube materials. Phys. Rev. Lett. 2010, 104. [CrossRef] [PubMed]

54. Song, Y.S.; Youn, J.R. Influence of dispersion states of carbon nanotubes on physical properties of epoxy nanocomposites. Carbon 2005, 43, 1378-1385. [CrossRef]

55. Roy, A.K.; Farmer, B.L.; Varshney, V.; Sihn, S.; Lee, J.; Ganguli, S. Importance of interfaces in governing thermal transport in composite materials: Modeling and experimental perspectives. ACS Appl. Mater. Interfaces 2012, 4, 545-563. [CrossRef] [PubMed]

56. Zhong, H.; Lukes, J.R. Interfacial thermal resistance between carbon nanotubes: Molecular dynamics simulations and analytical thermal modeling. Phys. Rev. B 2006, 74. [CrossRef]

57. Duong, H.M.; Yamamoto, N.; Bui, K.; Papavassiliou, D.V.; Maruyama, S.; Wardle, B.L. Morphology effects on nonisotropic thermal conduction of aligned single-walled and multi-walled carbon nanotubes in polymer nanocomposites. J. Phys. Chem. C 2010, 114, 8851-8860. [CrossRef]

58. Varshney, V.; Patnaik, S.S.; Roy, A.K.; Farmer, B.L. Modeling of thermal conductance at transverse CNT-CNT interfaces. J. Phys. Chem. C 2010, 114, 16223-16228. [CrossRef]

59. Gharib-Zahedi, M.R.; Tafazzoli, M.; Böhm, M.C.; Alaghemandi, M. Transversal thermal transport in single-walled carbon nanotube bundles: Influence of axial stretching and intertube bonding. J. Chem. Phys. 2013, 139. [CrossRef] [PubMed]

60. Gomez-Navarro, C.; Weitz, R.T.; Bittner, A.M.; Scolari, M.; Mews, A.; Burghard, M.; Kern, K. Electronic transport properties of individual chemically reduced graphene oxide sheets. Nano Lett. 2007, 7, 3499-3503. [CrossRef] [PubMed]

61. Becerril, H.A.; Mao, J.; Liu, Z.; Stoltenberg, R.M.; Bao, Z.; Chen, Y. Evaluation of solution-processed reduced graphene oxide films as transparent conductors. ACS Nano 2008, 2, 463-470. [CrossRef] [PubMed]

62. Xu, Z.; Zhang, Y.; Li, P.; Gao, C. Strong, conductive, lightweight, neat graphene aerogel fibers with aligned pores. ACS Nano 2012, 6, 7103-7113. [CrossRef] [PubMed]

(C) 2016 by the authors; licensee MDPI, Basel, Switzerland. This article is an open access article distributed under the terms and conditions of the Creative Commons Attribution (CC-BY) license (http:/ / creativecommons.org/licenses/by/4.0/). 